\title{
Estudo da via intramedular como protocolo alternativo para a infusão de fluidos em cães jovens
}

\section{Clinical study of intramedullary route as an alternative for fluid administration in young dogs}

Pedro Luiz de CAMARGO ${ }^{1}$; Helena FERREIRA ${ }^{2}$; Carmen Esther Grumadas MACHADO'; Domingos José STURION'; Janis Regina Messias GONZALES ${ }^{2}$

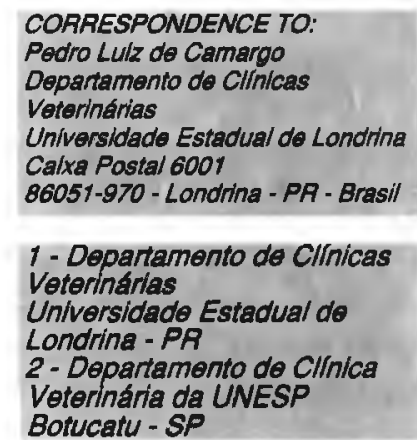

\section{RESUMO}

O uso da via intramedular foi avaliado em 31 cães clinicamente normais, de até três meses de idade e com peso entre 920 e $3.385 \mathrm{~g}$, divididos, aleatoriamente, em grupo 1 (G1), com 15 animais, e grupo 2 (G2), com 16. Aqueles do G1 foram tratados com $\mathrm{NaCl}$ a $0,9 \%$ e os do $\mathrm{G} 2 \mathrm{com}$ sangue total. Foram anotados os tempos gastos para implantação da agulha, as velocidades máximas de infusão obtidas e as ocorrências havidas durante o período de infusão. Todos os animais foram avaliados clinicamente durante os 30 dias de experimentação e por meio de radiografias nos dias 15 e 30 do experimento. Constatou-se que a técnica é de fácil e rápida execução e pouco cruenta. Os resultados observados indicam que a via intramedular é segura, sendo uma alternativa valiosa à via intravenosa no tratamento de filhotes de cães com graves alterações hemodinâmicas.

UNITERMOS: Medula óssea; Transfusão; Técnicas; Cães.

\section{INTRODUÇÃo}

É comum em situações emergenciais envolvendo pequenos animais, a ocorrência de transtornos hemodinâmicos que culminam com hipovolemia e hipotensāo. Nestas condições, a fluidoterapia e a aplicação de medicamentos devem ser feitas pela via intravenosa, visto que as vias oral, subcutânea ou intraperitoneal, apesar de exeqüíveis, são ineficientes para expansāo de volume circulante ou para uma aplicação rápida de $\operatorname{drogas}^{10}$. Porém, a hipovolemia e hipotensão determinam o colabamento das veias periféricas, tornando a punção venosa demorada, difícil ou mesmo impossível. Como agravante tem-se, nestas condições, a facilidade com que as veias se rompem à injeçāo rápida de líquidos e o pequeno número de vasos utilizáveis para venóclise no cão. A aplicação por via intramedular seria uma alternativa viável nestas situaçōes, já que é de fácil execução ${ }^{1.2 .9 .10}$, seus vasos não são sujeitos à ruptura ${ }^{8.9,12}$ e sua eficiência é similar àquela da via intravenosa $a^{3,4,6,7,8,9,13,14,15,16}$. Além disso, a firme fixação da agulha permite a continuidade da fluidoterapia, mesmo durante movimentação excessiva do animal ${ }^{2,11,16}$.

As contra-indicações para o seu emprego são as anormalidades esqueléticas, fraturas recentes e presença de bacteremia ou infecções tegumentares no local da punção ${ }^{10,11}$. As possíveis complicações posteriores seriam o tromboembolismo gorduroso pulmonar $^{17}$, a osteomielite e os abscessos locais $^{11,12}$.

Este estudo objetivou verificar o grau de dificuldade de execução da técnica, aferir a velocidade máxima de infusão possível de ser obtida, avaliar a viabilidade de manter uma agulha implantada no fêmur por determinado período e verificar a ocorrência de complicaçōes posteriores ao seu emprego.

\section{MATERIAL E MÉTODO}

Utilizaram-se 31 cães clinicamente normais, com idade inferior a 90 dias e com peso variando entre 920 e $3.385 \mathrm{~g}$, distribuídos 15 nos grupos 1 (G1) e 16 no 2 (G2). Os animais do G1 receberam no mínimo $10 \%$ do seu peso em $\mathrm{NaCl}$ a $0,9 \%^{* *}$ e aqueles do $\mathrm{G} 2,3 \%$ em sangue total. Foi feita uma aplicaçāo prévia $0,3 \mathrm{mg} / \mathrm{kg}$ de acepromazina $0,2 \% * * *$ (via intravenosa) e $0,5 \mathrm{ml}$ de lidocaína a $0,5 \% * * * *$ no local.

Usaram-se agulhas $(40 \times 10)$, com mandril***** e que foram implantadas pelo aspecto medial do trocanter maior do fêmur, através da sua fossa trocantérica. Com o animal em decúbito lateral e o membro posterior em posição neutra, faziase uma leve rotação medial do membro para afastar a agulha do nervo ciático. A introdução da agulha era feita com movimentos de rotação parcial e com pressão suficiente para a penetração óssea ${ }^{10}$, sendo cronometrado o tempo de execuçāo da técnica. Nesta fase, mantinha-se a agulha perfeitamente paralela ao osso, caso contrário ela poderia transpassá-lo 
CAMARGO, P.L.; FERREIRA, H.; MACHADO, C.E.G.; STURION, D.J.; GONZALES, J.R.M. Estudo da via intramedular como protocolo alıernativo para a infusão de fluidos em cāes jovens. Braz. J. vet. Res. anim. Sci. São Paulo, v.33, n.4, p.235-238, 1996.

durante a penetraçāo.

Após verificação radiográfica do correto posicionamento da agulha, iniciava-se a infusão e aferia-se a velocidade máxima de infusāo obtida por açāo da força de gravidade. Isto feito, reduzia-se esta velocidade a um nível compatível com a duraçāo da fluidoterapia, que foi de no mínimo duas horas.

Terminada a infusão avaliava-se o tempo de remissão da dor, observavam-se a marcha e a possível presença de alterações locais. Os animais foram avaliados fisicamente durante 30 dias e por radiografias nos dias 15 e 30 do experimento.

\footnotetext{
** Laboratórios Hales \& Istar S.A.

*** Acepran 0,2\% - Laboratório Andrômaco Ltda.

**** Xilocaína 0,5\% - Laboratório Merrel Lepetit

***** BD - Benctron \& Dickinson Inds. Cirúrgicas Ltda.
}

\section{RESULTADOS}

O tempo de execução da técnica variou de 9 a 75 segundos (média de 22,54 segundos). No G1 ocorreram oito falhas de implantação de agulha em 23 tentativas $(34,78 \%)$ e no $\mathrm{G} 2$ duas falhas em 28 tentativas $(11,11 \%)$.

A dor à implantaçāo foi moderada, visto que não foi necessário contenção enérgica para sua execução ou para continuidade da infusão. As velocidades máximas de infusão variaram entre 59,50 e $379,56 \mathrm{ml} / \mathrm{kg} / \mathrm{h}$ (média $137,68 \mathrm{ml} / \mathrm{kg} / \mathrm{h}$ ) com $\mathrm{NaCl} 0,9 \%$ e de 39,39 a $161,00 \mathrm{ml} / \mathrm{kg} / \mathrm{h}$ (média de 99,04 $\mathrm{ml} / \mathrm{kg} / \mathrm{h}$ ) com sangue total. Os animais demonstraram dor intensa quando da mensuração das velocidades máximas e à infusão, sob pressão, para lavagem da agulha.

Em um animal do G1 conseguiu-se infundir apenas $25 \mathrm{ml}$ de $\mathrm{NaCl}$ a $0,9 \%$ a uma velocidade de $19,31 \mathrm{ml} / \mathrm{kg} / \mathrm{h}$. O membro empregado tornou-se edemaciado após a tentativa de infundir o líquido sob pressão. Neste animal o procedimento foi interrompido, ficando ainda a agulha implantada por $2 \mathrm{~h}$ e $10 \mathrm{~min}$.

O tempo de permanência da agulha variou de $2 \mathrm{~h}$ e $10 \mathrm{~min}$ a 3h. Durante este período todos animais dormiram, demonstrando pouco desconforto. Alguns caminharam e assumiram posição para defecação e micção ainda com a agulha implantada.

No G2 ocorreram quatro obstruçōes da agulha ou do equipo, porém, a passagem de mandril pela agulha e a lavagem com solução salina heparinizada solucionaram o problema.

Em dois animais do Gl ocorreu edemaciaçāo do membro infundido apesar da correta implantação da agulha. Destarte, cessada a infusão, o edema regrediu rapidamente.

Em cinco animais do G1 e dois do G2 ocorreu refluxo de líquido e infiltração no tecido subcutâneo local. Estas alteraçōes foram discretas e cessaram com a diminuição da velocidade de gotejamento ou após o término da infusão.

Após a remoção da agulha, os animais apresentaram claudicação (moderada a acentuada) e discreta algia local. Nas horas subseqüentes observaram-se moderada e intermitente claudicação, leve dor à palpação e discreto aumento de volume no local da punção. Estes sintomas perduraram por 18 a 48 horas e, em dois animais, até 72 horas após o procedimento. Após 30 dias de acompanhamento nāo se notava nenhuma alteração no membro empregado para infusão.

\section{DISCUSSÃO}

O tempo médio despendido com a implantação da agulha (22,54 segundos) pela fossa trocantérica do fêmur, como descrito por Otto et al. ${ }^{10}$ (1989), reflete a facilidade de execuçāo e a adequação da técnica para uso em situaçōes emergenciais. Apesar desta facilidade, ocorreram falhas de implantação em sete animais. Porém, em cinco deles o acerto foi obtido já na segunda tentativa, em um deles na terceira e em um outro foram necessárias quatro tentativas. Estes erros deveram-se à obesidade, à massa muscular glútea desenvolvida ou ao pequeno tamanho do paciente, que dificultam a localização da fossa trocantérica. Contudo, a prática e a familiarização com a anatomia local diminuem a ocorrência de erros por estes fatores. Além disso, a repetição da técnica nāo causou qualquer complicaçāo posterior.

A confirmação da correta posição da agulha foi feita por meio de radiografias, contudo isto poderá ser feito baseando-se em características, próprias da implantação correta, como a perda de resistência à penetração da agulha, quando se adentra a cavidade medular ${ }^{16}$, a firme implantaçāo da agulha e a aspiraçāo de fragmentos de medula óssea e sangue, o que seria a confirmação definitiva da implantação correta ${ }^{5.11 \cdot 16}$. Estas características foram quase sempre observadas, e já se sabia do sucesso ou não da implantação mesmo antes da confirmação pelo exame radiográfico. Estas observaçōes serão úteis quando a confirmação radiográfica não for possível.

As velocidades recomendadas para expansão de volume em cães são de 60 a $100 \mathrm{ml} / \mathrm{kg} / \mathrm{h}$ para soluções isotônicas e de até $22 \mathrm{ml} / \mathrm{kg} / \mathrm{h}$ para sangue. Em apenas um animal a velocidade máxima obtida não foi adequada $(59,50 \mathrm{ml} / \mathrm{kg} / \mathrm{h})$, porém foi bem próxima do limite inferior recomendado. Nas 31 infusões realizadas, apenas uma foi malsucedida apesar da correta implantação da agulha e representou $3,22 \%$ do percentual de insucessos no experimento. Ocorrência semelhante não deve desestimular o emprego da via intramedular, já que se pode repetir o procedimento no osso contralateral ${ }^{11,16}$.

A dor à implantação da agulha não é fator limitante para o emprego desta via e não deve desencorajar seu uso, principalmente ao se considerar a gravidade das situações em que o uso da técnica é preconizado. A infusão sob pressāo é dolorosa, mas, como foi usada em procedimentos de curta duração, não interferiu na continuidade da fluidoterapia.

A manutenção da agulha durante a fluidoterapia foi pouco dolorosa, já que foi possivel mantê-la por $2 \mathrm{~h}$ e $10 \mathrm{~min}$ a $3 \mathrm{~h}$ sem maiores esforços de contenção. Sua firme fixação permite alguma movimentação do animal sem prejudicar a 
CAMARGO, P.L.; FERREIRA, H.; MACHADO, C.E.G.; STURION, D.J.; GONZALES, J.R.M. Estudo da via intramedular como protocolo alternativo para a infusão de fluidos em cāes jovens. Braz. J. vet. Res. anim. Sci. São Paulo, v.33, n.4, p.235-238, 1996.

fluidoterapia.

A ocorrência de tromboembolismo gorduroso pulmonar é sugerida na literatura e ocorreria entre algumas horas a três ou quatro dias após o manuseio do osso. Todavia, nenhum dos animais estudados apresentou qualquer alteração respiratória. Isto, associado à falta de relatos desta complicação, em situaçōes clínicas, indica que o risco de sua ocorrência após o emprego desta via é pequeno ou apenas hipotético.

Mesmo sem existir relatos na Medicina Veterinária, a osteomielite é uma complicação em potencial importante. Seus sintomas são dor e tumefação local, claudicação e febre. Ao exame radiográfico podem-se constatar reação periostal e lise óssea dentro de 10 a 14 dias pós-infecção. Nenhuma destas alterações foi observada nos animais utilizados, mesmo naqueles em que ocorreu infiltração de líquido no subcutâneo ou refluxo ao redor da agulha.

Demonstra-se, assim, que, empregando-se corretamente a técnica e observando-se preceitos básicos de anti-sepsia, pode- se diminuir ou suprimir a ocorrência de complicações.

\section{CONCLUSÕES}

Os resultados obtidos permitiram concluir que a técnica é de fácil e rápida execução. A obesidade, a massa muscular desenvolvida na região glútea e o pequeno porte do paciente dificultam a execução da técnica e favorecem o erro, porém a prática diminui a freqüência de erros por estes fatores. Além disso, a repetição da técnica não implica complicações posteriores. A firme fixação da agulha no caso é vantajosa, visto que permite alguma movimentação do animal sem prejuízo à fluidoterapia. As velocidades de infusão obtidas por esta via quase sempre são adequadas para rápida expansão de volume. A ausência de alterações após seu emprego permite afirmar que a via intramedular é segura para uso em filhotes de cães.

\section{SUMMARY}

Intramedullary infusion technique was evaluated in 31 dogs less than three months of age, weighing 920 to 3,385 grams and showing no clinical signs of disease. They were randomly divided into group 1 (G1) and group 2 (G2) of 15 and 16 dogs, respectively. $\mathrm{G} 1$ received $0.9 \% \mathrm{NaCl}$ solution and $\mathrm{G} 2$ received whole blood. The time necessary to perform intramedullary needle placement, maximum intramedullary infusion rate and any other event observed during the infusion period were recorded. The dogs were clinically evaluated on a daily basis during 30 days and radiographies were taken on days 15 and $\mathbf{3 0}$ after the procedure. Intramedullary infusion technique was easily accomplished and rapidly performed. Our results show that intramedullary route is safe and may be of great value as an alternative on the treatment of young dogs with critical hemodynamic alterations when the intravenous route is not accessible.

UNITERMS: Bone marrow; Transfusion; Techniques; Dogs.

\section{REFERÊNCIAS BIBLIOGRÁFICAS}

1-BRICKMAN, K.R.; REGA, P.; GUINNESS, M. A comparative study of intraosseous versus peripheral intravenous infusion of diazepam and phenobarbital in dogs. Annals of Emergency Medicine, v.16, n.10, p.1141-4, 1987.

2-CAMARGO, P.L.; FERREIRA, H. Aplicação de drogas e fluidoterapia pela Via Intramedular em cá intoxicado por organofosforado: relato de caso. In: CONGRESSO BRASILEIRO DA ANCLIVEPA, 16., Goiânia 1994. Livro de Resumo. Goiânia, ANCLIVEPA, 1994

3-CLARK, C.H.; WOODLEY, C.H. The absorption of red blood cells after parenteral injection at various sites. American Journal of Veterinary Research, v.20, p.1062-6, 1959.

4-CORLEY, E.A. Intramedullary transfusion in small animals. Journal of the American Veterinary Medical Association, v.142, n.9, p.1005-6, 1963.

5-HODGE, D.; DELGADO-PAREDES, C.; FLEISHER, G. Intraosseous infusion flow rates in hypovolemic "pediatric" dogs. Annals of Emergency Medicine, v.16, n.3, p.305-7, 1987.

6-MORRIS, R.E.: SCHONFELD, D.N.; HAFTEL, A.J. Treatment of hemorrhagic shock with intraosseous administration of crystalloid fluid in the rababbit model. Annals of Emergency Medicine, v.16, n.12, p.1321-4, 1987.

7-NEISH, R.S.; MACOON, M.G.; MOORE, J.W.M.; GRAEBER, G.M Intraosseous infusion of Hipertonic Glucose and Dopamine. American Journal of Diseases of Children, v.142, n.7, p.878-80, 1988
8-OKRASINSKI, E.B.; KRAHWINKEL, D.J.; SANDERS, W.L. Treatment of dogs in hemorragic shock by intraosseous infusion of hypertonic saline and dextran. Veterinary Surgery, v.21, n.1, p.20-4, 1992

9-ORLOWSKI, J.P.; POREMBKA, D.T.; GALLAGHER, J.M. Comparasion study of intraosseous, central intravenous and peripheral intravenous infusions of emergency drugs. American Journal of Diseases of Children, v.144, p.112-7, 1990 .

10-OTTO, C.M.; KAUFMAN, G.C.; CROWE JUNIOR, D.T. Intraosseous infusion of fluids and therapeutics. Compendlum on Continuing Education for the Practicing Veterinarian, v.11, n.4, p.421-30, 1989.

11-QUILLIGAN JUNIOR, J.J.; TURKEL, H. Bone marrow infusion and its complications. American Journal of Diseases of Children, v.71, n.5, p.457 $65,1946$.

12-ROSETTI, V.A.; THOMPSON, B.M.; MILLER, J.; MATTER, J.R APRAHAMIAN, C. Intraosseous infusion: an alternative route of pediatric intravascular access. Annals of Emergency Medicine, v.14, n.9, p.885-8, 1985

13-SPIVEY, W.H.; LATHERS, C.M.; MALONE, D.R.; UNGER, H.D.; BHAT, S.; MCNAMARA, R.N.; SHOFFSTALL, J,; TUMER, N. Comparasion of intraosseous, central and perifheral routes of sodium bicarbonate administration during CPR in pigs. Annals of Emergency Medicine, v.14, n.12, p.1135-40, 1985 .

14-SPIVEY, W.H.; UNGER, H.D.; LATHER, C.M.; McNAMARA, R.M. Intraosseous Diazepam suppression of Pintylenetetretranol: induced epileptogenic activity in pigs. Annals of Emergency Medicine, v.16, n.2, p.156-9, 1987. 
CAMARGO, P.L.; FERREIRA, H.; MACHADO, C.E.G.; STURION, D.J.; GONZALES, J.R.M. Estudo da via intramedular como protocolo alternativo para a infusão de fluidos em cães jovens. Braz. J. vet. Res. anim. Sci. São Paulo, v.33, n.4, p.235-238, 1996.

15-TOCANTINS, L.M. Rapid absorption of substances injected into the bone marrow. Proceedings of the Society for Experimental Biology and Medicine. v.45, p. $292-6,1940$.

16-TOCANTINS, L.M. Infusions of blood and other fluids into the general circulation via the bone marrow: technique and results. Surgery, Gynecology and Obstetrics, n.73, p.281-7, 1947

17-WILE, V.J.; SHAMBERG, I.C. Pulmonary fat embolism following infusions via the bone marrow. Journal of Investigative Dermatology, v.5, p.175-7, 1942. 